\title{
Effects of harmful factors and alcohol consumption by mother concerning the physical and mental health of her child
}

Ioana Mihaela Tomulescu

\author{
From $1^{\text {st }}$ International Congress on Neurobiology and Clinical Psychopharmacology \\ and European Psychiatric Association Conference on Treatment Guidance \\ Thessaloniki, Greece. 19-22 November 2009
}

\section{Background}

Mental retardation is a developmental disability that first appears at children under the age of 18 . About $5 \%$ of the mentally retarded population is affected by severe mental retardation. Approximately $20 \%$ of the population with mental deficience presents moderate mental retardation and about $75 \%$ have mild mental retardation. A very important factor that cause mental retardation of child is the alcohol consumption by mother on the pregnancy period.

Fetal alcohol syndrome (FAS) is a group of birth defects occurring in an infant as a result of maternal alcohol abuse during pregnancy. This syndrome was first described in 1968. It is currently the leading cause of mental retardation in western civilisation, outranking Down syndrome.

\section{Materials and methods}

To realise this study, we investigated 596 children hospitalized on period of 1999-2001 in Neuropsychiatry Infantile Section of Neurology and Psychiatry Clinical Hospital from Oradea. Among these, 393 have different degree of mental retardation. We realised family investigation and followed the hereditary antecedents, the harmful factors, alcohol consumption by mother, smoking and social and economic situation of families with mentally retarded children.

\section{Results}

Among 393 children with mental retardation, 216 have mild mental retardation (63 of them have different

\section{Department of Biology, Faculty of Sciences, University of Oradea, Oradea,} Romania harmful factors in their families), 87 have moderate mental retardation ( 40 of them have different harmful factors in their families) and 90 have severe mental retardation (33 have different harmful factors in their families).

\section{Conclusions}

This study shows that in general, when in a family exists one child with mental retardation there exist at least one toxic factor. So, the harmful factor can be added hereditary antecedents and particularly the advanced age of mother. Fetal alcohol syndrome is a group of birth defects occurring in an infant as a result of maternal alcohol abuse during pregnancy period.

Fetal alcohol syndrome is completely preventable. Prognosis depends on the degree of mental and neurological development. The rate of this harmful factor is increased in population from rural environment. FAS is a public health issue.

Published: 22 April 2010

\section{References}

1. Hankin JR: Heeding the alcohol beverage warning label during pregnancy: multiparae vs. Nulliparae. J Stud Alcohol. 1996, 57(2):171-177.

2. Makela P, Valkonen T, Martelin T: Contribution of deaths related to alcohol used to socioeconomic variation in mortality: register based follow up study. BMJ 1997, 315(7102):211-216.

3. Tomulescu IM: Mental retardation and other associated genetic diseases with it in Bihor county, Romania. University of Oradea Publishing House 2004.

doi:10.1186/1744-859X-9-S1-S180

Cite this article as: Tomulescu: Effects of harmful factors and alcohol consumption by mother concerning the physical and mental health of her child. Annals of General Psychiatry 2010 9(Suppl 1):S180. 